\title{
Mathematical Model and Simulation of Gas Hydrate Reservoir Decomposition by Depressurization
}

\author{
J. Zhao*, D. Shi and Y. Zhao \\ Mining Technology Institute, Taiyuan University of Technology, Taiyuan 030024 - PR China \\ e-mail: zjz1104@163.com -Dingxian_shi@yahoo.com-y-s-zhao@263.net \\ * Corresponding author
}

\begin{abstract}
Résumé - Modèle mathématique et simulation de dépressurisation et de décompression d'un réservoir d'hydrates de méthane - Le modèle numérique présenté ici simule la dépressurisation d'hydrates de méthane dans un réservoir confiné ; il se base sur le principe de conservation de la masse en milieu poreux, en intégrant la théorie de l'écoulement polyphasique et la cinétique de dissociation des hydrates de méthane. La méthode implicite et universelle des différences finies est utilisée et le programme informatique qui s'y rapporte est développé. Lors de l'exploitation du réservoir d'hydrates de méthane, la répartition et les changements physiques sont analysés et les lois sur la dissociation des hydrates de méthane et la production de gaz sont étudiées à partir des calculs. Une simulation numérique montre que la pression dans le réservoir diminue lentement, ce qui permet au réservoir de se stabiliser et diminue inévitablement le rendement de l'exploitation d'hydrates de méthane lors du processus de dépressurisation. Le rythme de production du gaz est contrôlé par la pression au puits. Les résultats présentés montrent comment ce modèle peut être utilisé pour proposer une pression abaissée au fond du puits afin de récupérer l'hydrate de méthane. De plus, ces résultats démontrent qu'ils dépendent des propriétés des hydrates de méthane et du réservoir.
\end{abstract}

Abstract - Mathematical Model and Simulation of Gas Hydrate Reservoir Decomposition by Depressurization - The numerical model for the depressurization of methane hydrates in a confined reservoir is presented based on mass conservation in porous media, incorporating multiphase flow theory and kinetics of gas hydrate dissociation. The universal implicit difference method is adopted, and the corresponding computer program is developed. During the production of the hydrate reservoir, distribution and the physical changes are analyzed and the gas hydrate dissociation and gas production law are studied from the computation. A numerical simulation shows that the reservoir pressure is descending slowly, which benefits the stabilization of the reservoir and inevitably decreases the efficiency in the production of gas hydrates in the depressurizing process. The gas production rate is controlled by the well pressure. The results are presented to show how this model may be used to estimate a lower downhole pressure of the well for hydrate recovery and how these results depend on reservoir and hydrate properties. 


\section{SYMBOL LISTS}

$A_{\mathrm{s}} \quad$ Specific surface area of reaction $\left(\mathrm{m}^{-1}\right)$

$K_{\mathrm{d}} \quad$ Dissociation rate constant $\left(\mathrm{kg} / \mathrm{m}^{2} \cdot \mathrm{Pa} \cdot \mathrm{s}\right)$

$k \quad$ Absolute permeability of the media $\left(\mathrm{m}^{2}\right)$

$k_{\mathrm{r}} \quad$ Relative permeability

$k_{\mathrm{D} 0} \quad$ Absolute permeability at zero hydrate saturation $\left(\mathrm{m}^{2}\right)$

$m \quad$ Dissociation mass $(\mathrm{kg})$

$N \quad$ Decrease index of permeability

$n \quad$ Hydrate number

$p \quad$ Pressure (MPa)

$p_{\mathrm{wf}} \quad$ Local pressure in the core (MPa)

$p^{\mathrm{e}} \quad$ Equilibrium pressure of hydrate (MPa)

$q \quad$ Source-sink $\left(\mathrm{kg} / \mathrm{m}^{3} \cdot \mathrm{s}\right)$

$r_{\mathrm{e}} \quad$ Equivalent radius (m)

$r_{\mathrm{w}} \quad$ Radius of well (m)

$S \quad$ Saturations

$S_{\mathrm{wr}} \quad$ Irreducible saturations of water

$S_{\mathrm{gr}} \quad$ Irreducible saturations of gas

$t \quad$ Time (s)

$\Phi \quad$ Porosity

$\rho \quad$ Density $\left(\mathrm{kg} / \mathrm{m}^{3}\right)$

$\mu \quad$ Viscosity of gas (Pa.s)

\section{Superscripts}

$0 \quad$ Initial time

$k \quad$ Iteration step of $k$

$n \quad$ Iteration step $n$ time

\section{Subscripts}

$\begin{array}{ll}H & \text { Hydrate } \\ w & \text { Water } \\ g & \text { Gas }\end{array}$

\section{INTRODUCTION}

Gas hydrates widely exist in deep-sea sediments and permafrost land with huge reserves, causing widespread concern in the scientific and engineering communities. Research in gas hydrate reservoir production technology has become a hot topic for development of new energy. However, hydrate production technology is very poor at the practical stage because of the complicated conditions of gas hydrate reservoirs and the uncertain results of events such as submarine disasters, climate change, etc., after the production.
So far, only limited in situ cases of hydrate exploitation have been practiced such as the Mallik site in Canada recently. Relative to the phase equilibrium study, the three common means of hydrate dissociation are the depressurization method, inhibitor injection method, and thermal stimulation method (Klauda et al., 2005; Sloan et al., 2008). Among these three dissociation techniques, depressurization can lower the pressure of the hydrate reservoirs, push the hydrate out of the equilibrium region and lead to its dissociation. Because there is no extra heat introduced into the reservoir, the heat of the dissociation must be supplied from the surrounding formation. Many studies have indicated that it could be a rate-controlling step in the overall dissociation process. For example, Clarke et al. $(2005,2001)$ extended Kim's work and calculated the intrinsic kinetic constant and activation energy by eliminating the influence of mass transformation or thermal transformation. Therefore, this technique could be attractive primarily when a large surface area exists for heat transfer and dissociation (Kehua et al., 2010; Ayhan, 2010). The presence of a free-gas zone beneath the hydrate may be essential to the success of the depressurization method.

Makogon (2010) and Sloan et al. (2008) provided extensive reviews of hydrate formation and dissociation processes. The hydrate dissociation process by depressurization has been studied by a number of authors. It is customarily assumed that the process of hydrate dissociation by a pressure decrease is analogous to the process of solid melting. Makogon et al. (2001) used the classical Stefans problem for melting to describe the process of hydrate dissociation. The present study is concerned with the question of natural gas production with constant well output from a hydrate reservoir. The case that the reservoir is partially saturated with hydrate, and the reservoir contains pressurized natural gas is considered. The linearized form of the governing equation as reported by Makogon et al. (2001) is used in the analysis.

From the viewpoint of material conservation, the production of gas hydrates is actually a process of hydrate dissociation in porous media and the migration of fluid. The two processes are restrained by each other. Thus, the study of hydrate distribution and gas with the water two-phase migration law is of great significance for the understanding of the nature of the hydrate reservoir dissociation. This work is to develop a mathematical model of hydrate dissociation and gas-water two-phase flow based on the theory of hydrate multiphase flow during the reservoir depressurization process. A strongly nonlinear numerical dispersion of the universal implicit difference method is adopted and the corresponding computer program is developed. During the production of hydrate, the reservoir distribution and the physical changes are analyzed. 


\section{MATHEMATICAL MODEL}

\subsection{Physical Basis Conditions}

Hydrate reservoir depressurization is a complex physicalchemical process which involves dissociation and reformation, heat transfer, deformation of the porous medium, migration of gas with water and other aspects. In order to make the mathematical model more accurate and simplified, some basic assumptions are introduced as follows:

- the solid hydrate is considered as a part of the pores in consideration of the gas, water and hydrate phase;

- the hydrate phase is not participating in flow and gas with water following Darcy's law;

- the gravity and capillary forces are not considered;

- the reformation of hydrate after dissociation at suitable temperature and pressure, and thermal effects of dissociation are not considered;

- the Thomson throttling effect in the flow process is ignored.

\subsection{Basic Governing Equations}

Hydrates constantly reduce as dissociation of the gas hydrate reservoir while gas with water as the products of dissociation are also changing thanks to seepage. By the continuity at $\Delta t$ time steps, the cumulative unit body mass of each phase should be equal to its dissociation and incremental quality of inflow and outflow. So, the mass balance equations for gas, water and hydrate flow through the porous medium can be written as:

$$
\left\{\begin{array}{l}
\nabla\left(\rho_{g} \frac{k k_{r g}}{\mu_{g}} \nabla p\right)+q_{g}+m_{g}=\frac{\partial}{\partial t}\left(\rho_{g} \phi S_{g}\right) \\
\nabla\left(\rho_{w} \frac{k k_{r w}}{\mu_{w}} \nabla p\right)+q_{w}+m_{w}=\frac{\partial}{\partial t}\left(\rho_{w} \phi S_{w}\right) \\
-m_{H}=\frac{\partial}{\partial t}\left(\rho_{H} \phi S_{H}\right)
\end{array}\right.
$$

The equations consider the compressibility and the relative permeability of fluid, hydrate and porous media. Each parameter in the equation is the function of unknowns such as density, porosity and relative permeability. Hence, the equations are significantly nonlinear. Each parameter satisfies the following relationship:

$$
\left\{\begin{array}{l}
\rho_{\alpha}=\rho_{\alpha}(p) \\
\mu_{\alpha}=\mu_{\alpha}(p) \\
k_{r \alpha}=k_{r \alpha}\left(S_{w}\right) \\
\phi=\phi(p)
\end{array} \quad(\alpha=w, g)\right.
$$

In addition, the pores are filled with hydrate, gas and water based on assumption (2). So, the saturation satisfies the following equation:

$$
S_{g}+S_{w}+S_{H}=1
$$

where $S_{\mathrm{g}}, S_{\mathrm{w}}$, and $S_{H}$ are saturation of gas, water and hydrate phases, respectively.

Energy balance at the dissociation front is given by:

$$
q_{g 1} \rho_{g} C_{p} T_{1}-q_{g 2} \rho_{g} C_{p} T_{2}-K_{1} \frac{\partial T_{1}}{\partial x}+K_{2} \frac{\partial T_{2}}{\partial x}=\Delta H m_{h}
$$

where $K_{n}$ is the heat conductivity in the gas and hydrate zone, $\rho_{g}$ is the density of natural gas in the dissociation zone, $m_{h}$ is the hydrate dissociation rate per unit area and $C_{P}$ is the heat capacity of natural gas. In Equation (4), the first term on the left hand side is the convective heat flux out of the dissociation front into the gas zone; the second term is the convective heat flux from the hydrate zone into the dissociation front. The third term is conductive heat flux from the dissociation front to the gas zone. The fourth term is the conductive heat flux from the hydrate zone into the dissociation front. The term on the right side is the rate of heat supplied for hydrate dissociation per unit time and area.

The governing equations of hydrate reservoir production are combined from Equation (1) to Equation (4), in which the number of unknowns is equal to the number of equations, so they can be solved.

\subsection{Auxiliary Equation}

The hydrate dissociation can be represented by the reaction:

$$
M(\mathrm{~g})+N_{H} \mathrm{H}_{2} \mathrm{O}(\mathrm{l}) \Leftrightarrow M \cdot N_{H} \mathrm{H}_{2} \mathrm{O}(\mathrm{s})
$$

where $M$ is the guest molecule in hydrate formation and $N_{H}$ (commonly known as the hydrate number) is the number of water molecules required per gas molecule to form a gas hydrate. The hydrate number for methane is approximately 6 (Sloan et al., 2008). The rate of gas generation caused by hydrate dissociation is given by the Kim-Bishnoi model (Kim et al., 1987):

$$
m_{H}=K_{d} A_{s}\left(p_{e}-p\right)
$$

According to the principle of mass conservation, i.e.:

$$
m_{H}=m_{w}+m_{g}
$$

where (Amyx et al., 1960):

$$
A_{s}=\left(\phi_{w g} / 2 k\right)^{\frac{1}{2}}
$$

The hydrate itself as a solid phase is not involved in flow and mobile spaces constantly grow during the dissociation process of the hydrate reservoir. Here, $k$ is the absolute 
permeability of the media and is modeled as (Masuda et al., 2005):

$$
k=k_{D 0}\left(1-S_{H}\right)^{N}
$$

where $k_{D 0}$ is the absolute permeability at zero hydrate saturation and $N$ is the permeability reduction index, which depends on the pore structure of the medium. Note that Equation (9) satisfies the expected limit at $S_{H}=0$ or 1 and the value of the permeability index $N$ is determined experimentally.

In this study, the relative permeability functions $k_{r g}\left(S_{w}, S_{g}\right)$ and $k_{r w}\left(S_{w}, S_{g}\right)$ are evaluated with Corey's model (Moridis et al., 2007):

$$
\begin{aligned}
& k_{r w}=k_{r w o} \bar{S}_{w}^{1 / 2}\left[1-\left(1-\bar{S}_{w}^{1 / m}\right)^{m}\right]^{2} \\
& k_{r g}=k_{r g o} \bar{S}_{g}^{1 / 2}\left(1-\bar{S}_{w H}^{1 / m}\right)^{2 m}
\end{aligned}
$$

Of which:

$$
\begin{aligned}
& \bar{S}_{w}=\frac{S_{w}-S_{w r}}{1-S_{w r}-S_{g r}} ; \bar{S}_{w H}=\frac{S_{w}+S_{H}-S_{w r}}{1-S_{w r}-S_{g r}} \\
& \bar{S}_{g}=\frac{1-S_{w}-S_{H}-S_{w r}}{1-S_{w r}-S_{g r}}
\end{aligned}
$$

\subsection{Boundary Conditions}

The initial conditions of the model are:

$$
\left\{\begin{array}{l}
p(x, y, t) \mathrm{।}_{t=0}=p^{0}(x, y) \\
S_{g}(x, y, t) \mathrm{I}_{t=0}=S_{g}^{0}(x, y) \\
S_{w}(x, y, t) \mathrm{।}_{t=0}=S_{w}^{0}(x, y) \\
S_{H}(x, y, t) \mathrm{।}_{t=0}=S_{H}^{0}(x, y)
\end{array}\right.
$$

Boundary conditions of the model

- internal boundary conditions:

$$
\left\{\begin{array}{l}
q_{\alpha}(x, y, t)=q_{\alpha}^{0}(t) \delta(x, y) \\
p_{w f}(x, y, t)=p_{w f}^{0}(t) \delta(x, y)
\end{array}\right. \text { or }
$$

- outer boundary conditions:

$$
\left\{\begin{array}{l}
\left.p(x, y, t)\right|_{(x, y) \in \Gamma}=p_{e}(x, y, t) \\
\partial p /\left.\partial n\right|_{x, y \in \Gamma}=0
\end{array}\right.
$$

\section{NUMERICAL METHOD OF SOLUTION}

The governing equations of hydrate reservoir production are a set of highly nonlinear equations. $\rho, \varphi, \mu$ and $k_{r}$ are functions of the unknown variables in which $k_{\mathrm{r}}$ has stronger nonlinearity. In the traditional IMPES, i.e. implicit pressure explicit saturation solution method, the adopted linearization method is an explicit approach which takes a uniform value of the upper time step. In addition to items of Darcy's flow, the items of production and dissociation themselves are functions of solved variables. So, the IMPES method undoubtedly causes a very considerable error of mass balance and then may sometimes not be solved due to divergence of solutions.

In this work, the universal implications difference method is adopted to deal with the nonlinear nature of the equations. $\delta p, \delta S_{\mathrm{w}}$, and $\delta S_{\mathrm{H}}$ are considered as unknown variables to couple equations and to be solved. The implicit item processing is undertaken on the flow coefficient, source-sink of wells, dissociation items and cumulative values. From the Taylor expansion, the first-order infinitesimal quantity is obtained. The first derivative takes the original order value rather than the values of the upper stage. Universal implication discretization equations are solved as follows:

$$
\begin{aligned}
& \nabla\left(T_{g}^{k+1} \nabla \delta P+\rho_{g}^{k+1} \lambda_{g w}{ }_{g w} \delta S_{w} \nabla P^{k}+\lambda_{g}^{k} \rho_{g}{ }_{g} \delta P \nabla P^{k}\right) \\
& +\left(\frac{\partial q_{g}}{\partial P}+\frac{\partial m_{g}}{\partial P}-\frac{1}{\Delta t}\left(\phi S_{g}\right)^{k} \rho_{g}^{\prime}-\frac{1}{\Delta t} \rho_{g}^{k+1} S_{g}^{k} \varphi^{\prime}\right) \delta P \\
& +\left(\frac{\partial q_{g}}{\partial S_{w}}+\frac{\partial m_{g}}{\partial S_{w}}+\frac{\left(\phi \rho_{g}\right)^{k+1}}{\Delta t}\right) \delta S_{w} \\
& +\left(\frac{\partial q_{g}}{\partial S_{H}}+\frac{\partial m_{g}}{\partial S_{H}}+\frac{\left(\phi \rho_{g}\right)^{k+1}}{\Delta t}\right) \delta S_{H} \\
& =\frac{1}{\Delta t}\left[\left(\phi \rho_{g} S_{g}\right)^{k}-\left(\phi \rho_{g} S_{g}\right)^{n}\right]-q_{g}^{k}-m_{g}^{k}-\nabla\left(T_{g} \nabla P\right)^{k} \\
& \nabla\left[T_{w}^{k+1} \nabla \delta P+\rho_{w}^{k+1} \lambda_{w w} \nabla P^{k}+\rho^{\prime}{ }_{w} \delta P \lambda_{w}^{k} \nabla P^{k}\right] \\
& +\left[\frac{\partial q_{w}}{\partial P}+\frac{\partial m_{w}}{\partial P}-\frac{1}{\Delta t}\left(\phi S_{w}\right)^{k} \rho^{\prime}{ }_{w}-\frac{1}{\Delta t} \rho_{w}^{k+1} S_{w}^{k} \varphi^{\prime}\right] \delta P \\
& +\left\{\frac{\partial q_{w}}{\partial S_{w}}+\frac{\partial m_{w}}{\partial S_{w}}-\frac{1}{\Delta t}\left(\phi \rho_{w}\right)^{k+1}\right\} \delta S_{w} \\
& +\left(\frac{\partial q_{w}}{\partial S_{H}}+\frac{\partial m_{w}}{\partial S_{H}}\right) \delta S_{H} \\
& =\frac{1}{\Delta t}\left[\left(\phi \rho_{w} S_{w}\right)^{k}-\left(\phi \rho_{w} S_{w}\right)^{n}\right]-q_{w}^{k}-m_{w}^{k}-\left(T_{w} \nabla P\right)^{k} \\
& {\left[\frac{\partial m_{H}}{\partial P}-\frac{1}{\Delta t}\left(\phi S_{H}\right)^{k} \rho_{H}^{\prime}-\frac{1}{\Delta t} \rho_{H}^{k+1} S_{H}^{k} \varphi^{\prime}\right] \delta P} \\
& +\left(\frac{\partial m_{w}}{\partial S_{w}}\right) \delta S_{w}+\left[\frac{\partial m_{H}}{\partial S_{H}}-\frac{1}{\Delta t}\left(\phi \rho_{H}\right)^{k+1}\right] \delta S_{H} \\
& =\frac{1}{\Delta t}\left[\left(\phi \rho_{H} S_{H}\right)^{k}-\left(\phi \rho_{H} S_{H}\right)^{n}\right]-m_{H}^{k}
\end{aligned}
$$

Among which: $T_{\alpha}=\rho_{\alpha} \cdot \lambda_{\alpha}, \lambda_{\alpha}=k k_{r \alpha} / \mu_{\alpha},(\alpha=w, g)$ 
Coupling (15-17) a set of algebraic equations can be taken. For the calculation domain containing NEL nodes, all linear equations of the first $k$ iterations can be written in the following matrix form:

$$
J^{k} \cdot \delta X=B^{k}
$$

Among which $\mathbf{J}$ is a $3 \times N E L$ order banded sparse matrix containing five blocks of diagonal structures, which contain a $N E L \times N E L$ three-dimensional non-symmetric sub-matrix. $\delta \mathbf{X}$ is the unknown columns' vector of increment between adjacency iterations in the all independent variables in which:

$$
\delta X_{i}=\left\{\delta p \quad \delta S_{w} \delta S_{H}\right\}, i=1,2, \ldots, N E L
$$

B is the known column vector of the right end. The GaussJordan elimination method of the pivoting element is adopted to solve the sparse matrix equation since the diagonal elements are different by several orders of magnitude.

After calculation, the solving variable is replaced, and $\mathbf{J}^{k+1}$ and $\mathbf{B}^{k+1}$ are re-calculated according to $\delta \mathbf{X}$. Then, the $k+1$ iteration step of the calculation begins until iteration to $\delta \mathbf{X} \rightarrow 0$. Hence, the iteration is implicitly deeper, the solution process is more stable and more accurate results are achieved.

\section{NUMERICAL SIMULATION}

According to the actual geological conditions of a hydrate reservoir (Klauda et al., 2005; Sloan et al., 2008), the calculation model is shown in Figure 1. The center of the model is the production well, which is a constant downhole pressure well. The well index is as follows:

$$
q_{g}=\frac{2 \pi k k_{r g} h}{\mu_{g} \Delta V \ln \frac{r_{e}}{r_{w}}}\left(P_{i, j}-P_{w f}\right)
$$

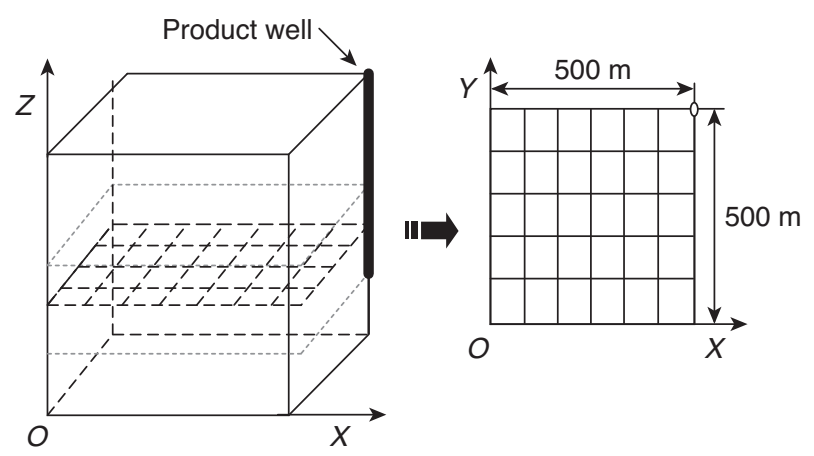

Figure 1

Schematic diagram of numerical model.
The $1 / 4 X-Y$ cross-section is selected for the calculation, taking into account the symmetry of the model. The boundaries of the model are set to be fixed conditions according to the geological conditions and the symmetry (see Fig. 1).

According to the actual situation, the porosity is set to be 0.25 , initial hydrate saturation to be 0.4 , gas saturation to be 0.6 , the absolute permeability without the presence of hydrate to be $1.0 \mu \mathrm{m}^{2}$ and the decrease index to be 5. Relative permeability of the gas-water is calculated according to Equation (8) in which water saturation is 0.2 , critical saturation of gas is 0.1 , the fitting parameter $m$ is 0.6 and the initial viscosity of water and gas is $1.0 \mathrm{MPa} \cdot \mathrm{s}$ and $0.018 \mathrm{MPa} \cdot \mathrm{s}$, respectively. Compressed coefficients of porosity, hydrate and water are obtained to be $1.0 \times 10^{-4} \mathrm{MPa}^{-1}, 2.0 \times 10^{-4} \mathrm{MPa}^{-1}$ and $4.0 \times 10^{-4} \mathrm{MPa}^{-1}$, respectively. Original formation pressure is 4.0 $\mathrm{MPa}$ and the method of production in gas wells is constant pressure in the downhole; and the pressure of the downhole of the well is $3.0 \mathrm{MPa}$. The initial temperature of the hydrate reservoir is $4.5^{\circ} \mathrm{C}$ (the corresponding hydrate phase equilibrium pressure is $3.875 \mathrm{MPa}$ ) (Sloan et al., 2008), hydrate reservoir thickness is $10 \mathrm{~m}$ and the dissociation constant (Lijun Yan et al., 2005) is $0.124 \times 10^{-13} \mathrm{~kg} / \mathrm{m}^{2} \cdot \mathrm{Pa} \cdot \mathrm{s}$. The hydrate number is 6 .

The initial flow vector field distribution of production is shown in Figure 2. The pressure gradient drives high-pressure gas filling the pores to flow. The flow speed is faster and the pressure drop is more noticeable to the well of the large pressure gradient. When the pressure is reduced to below hydrate dissociation pressure, the phase equilibrium condition of the hydrate is shifted in the pore and hydrate dissociation occurs. The gas and water of hydrate dissociation as output is involved in the flow moving to the well and output from the producing wells. The gas flow is not yet started. The pressure remains constant and the hydrate in the pores does not

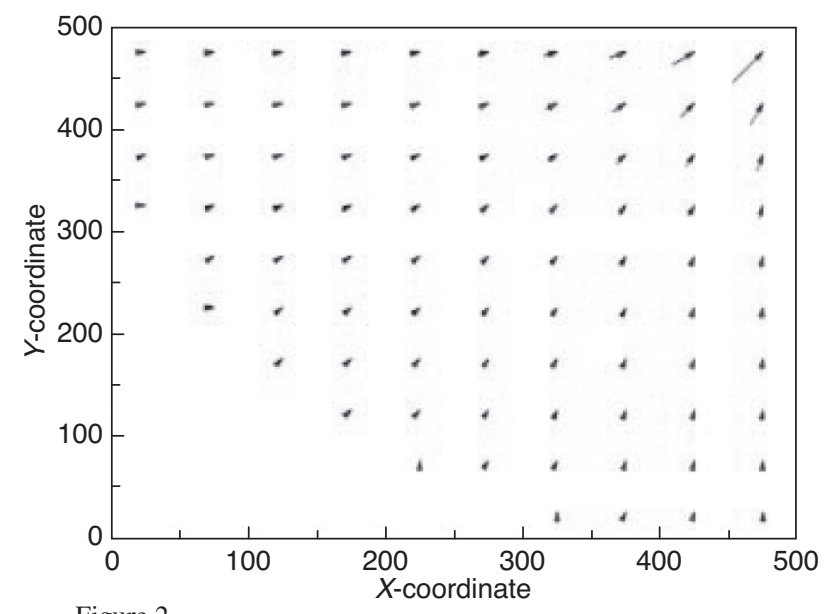

Figure 2

Vector of seepage at 60 days. 


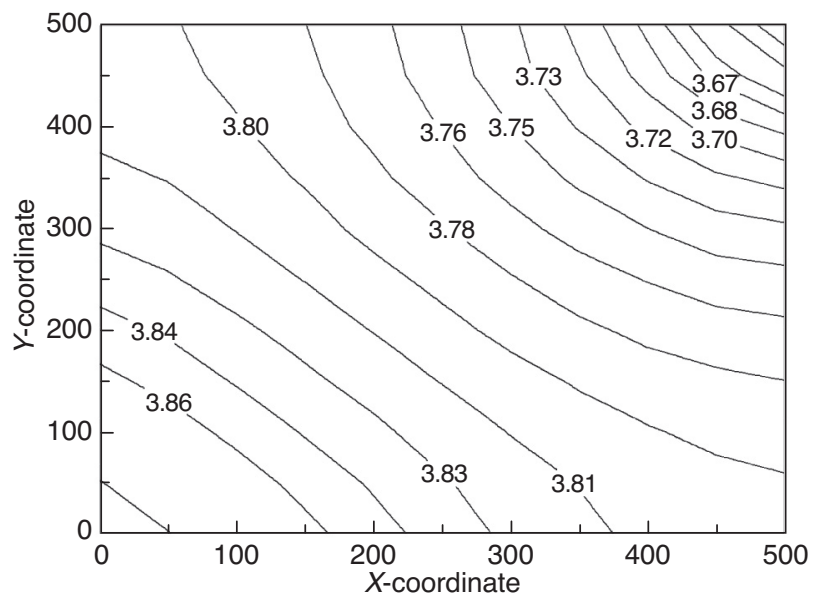

Figure 3

Pressure distribution at 120 days.

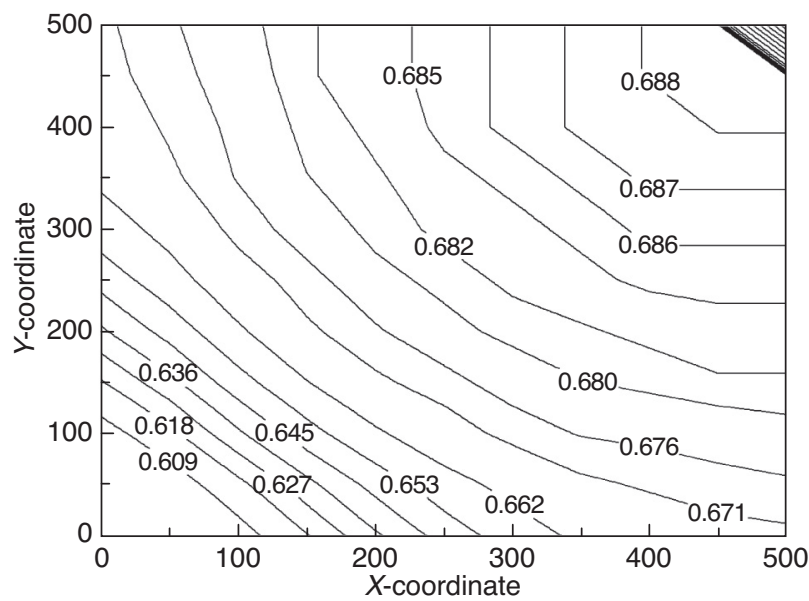

Figure 5

Gas saturation distribution at 120 days.

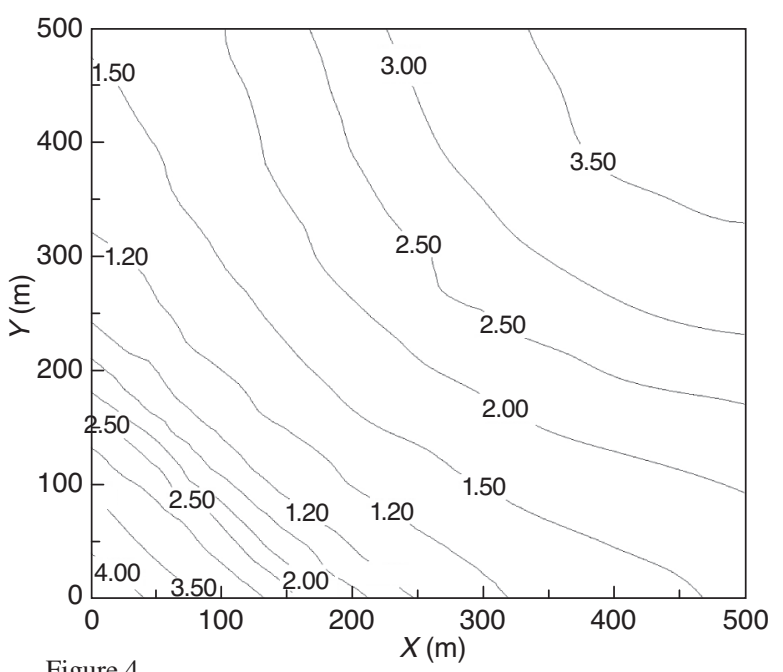

Figure 4

Temperature distribution at 120 days.

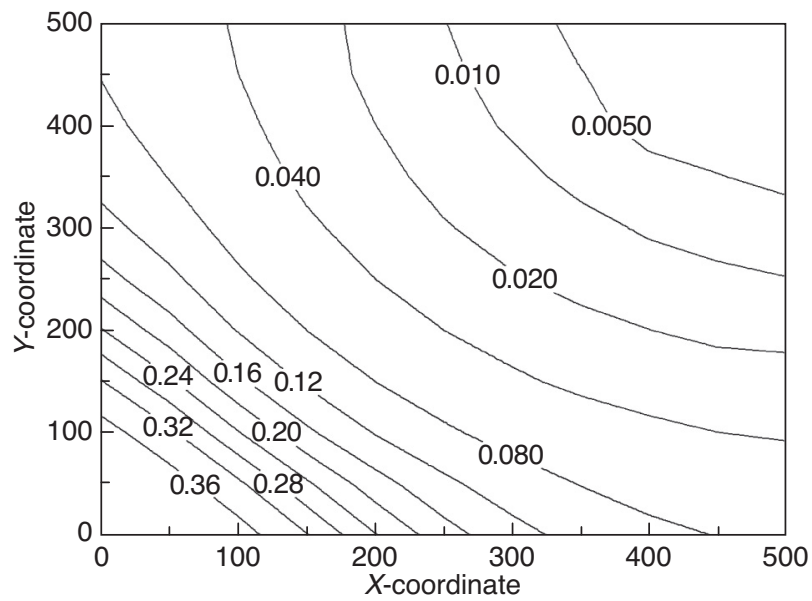

Figure 6

Hydrates saturation distribution at 120 days. dissociate due to the pressure gradient being zero far away from the wellbore.

Figures 3 and 4 show the evolution of the $P$ and $T$ distributions, respectively, after 120 days of the hydrate reservoir dissociation. The reservoir pressure drop is not large (the initial pressure is $4.0 \mathrm{MPa}$ ) and the spatial variations of the pressure gradient are also small. As gas hydrate dissociation is accompanied by the water output, the pressure drop is no doubt slower in the hydrate reservoir than in a conventional gas reservoir during gas production. Of particular interest is the $T$ distribution in Figure 4, which exhibits a minimum at the edge of the dissociation front and confirms the earlier statement (based on knowledge of the $\mathrm{CH}_{4}$-hydrate phase diagram) that no ice evolves during the dissociation process. At the front of hydrate dissociation, the temperature of the hydrate reservoir decreased rapidly. With the vector of fluid seepage increases the temperature gradually increased close to the wall hole. The temperature is close to the initial temperature of the reservoir near the wall hole.

Figures 5 and 6 are gas and gas hydrate saturation distribution, respectively. It can be seen that the gas hydrate dissociation is completed in the areas of rapidly decreased pressure around the well after production of 120 days. The dissociation front (where hydrate saturation is equal to the initial value) is gradually moving away from the well and the scope of dissociation is further expanding. The numerical results show that the hydrate dissociation is fully completed within the model and the residual gas and water in pores will continue to flow under a pressure gradient in the direction of the well after production of 10 months. 


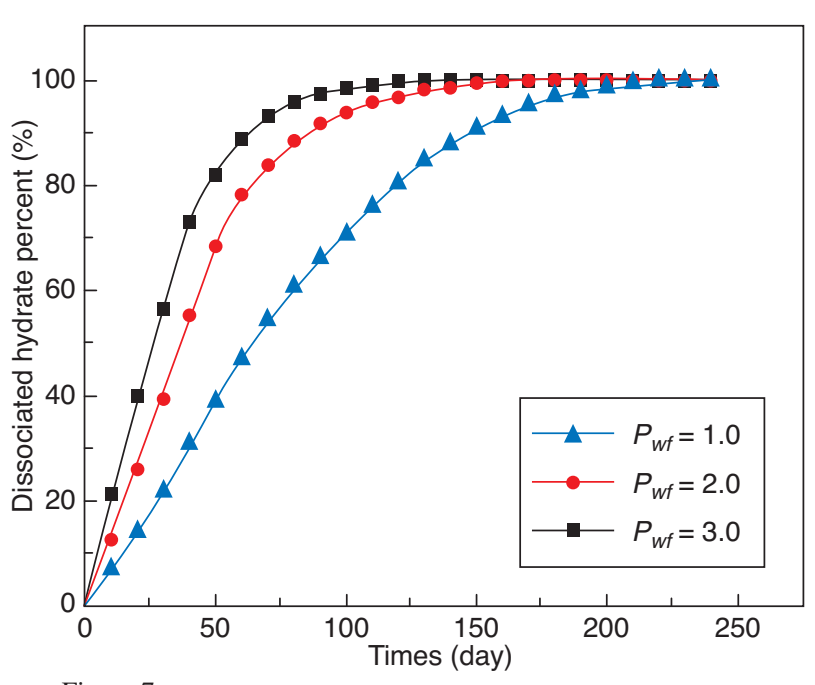

Figure 7

Hydrate dissociation at different product well pressure.

The total amount of hydrates dissociated in relation to the production time is shown in Figure 7 at different downhole pressures. It can be seen from the figure that the lower the downhole pressure, the faster the hydrate dissociation. The reason is that the formation of the gas flow gradient is larger to speed up the reservoir pressure drops which promote hydrate dissociation and the movement of the dissociation front is significantly accelerated at the lower downhole pressure.

\section{CONCLUSION}

The production mathematical model of gas hydrate reservoir depressurization is established and the nonlinear equations are solved by the introduction of a fully implicit finite difference method. The calculation method has good numerical stability and high accuracy. A corresponding numerical calculation program is prepared. The field variables in the spatial distribution with the time, dissociation front movement and transport law of gas with water can be accurately obtained from the calculation program.

The pressure drop of the hydrate reservoir is slowed down, which is helpful for controlling the reservoir pressure to ensure the security and stability of the production process according to the results of depressurizing the process. However, on the other hand, it will undoubtedly lead to a lengthy production process of the hydrate reservoir. So, a suitable wellbore pressure can effectively improve the dissociation rate and access to balance between production speed with the reservoir stability.

\section{ACKNOWLEDGMENTS}

Project 51074111, 2011011005 supported by the National Natural Science Foundation of China and Shanxi Natural Science Foundation.

\section{REFERENCES}

Amyx J.W., Bass D.M., Whiting R.L. (1960) Petroleum Reservoir Engineering-Physical Properties, McGraw-Hill Book Co., New-York.

Ayhan D. (2010) Methane hydrates as potential energy resource: Part 2 - Methane production processes from gas hydrates, Energy Convers. Manage. 51, 7, 1562-1571.

Clarke M.A., Bishnoi P.R. (2001) Determination of the intrinsic rate of ethane gas hydrate decomposition, Chem. Eng. Sci.55, 21, 4869-4883.

Clarke M.A., Bishnoi P.R. (2005) Determination of the intrinsic kinetics of $\mathrm{CO}_{2}$ gas hydrate formation using in situ particle size analysis, Chem. Eng. Sci. 60, 3, 695-709.

Kehua S., Changyu S., Xin Y., Guangjin C., Shuanshi F. (2010) Experimental investigation of methane hydrate decomposition by depressurizing in porous media with 3-Dimension device, J. Nat. Gas Chem. 19, 3, 210-216.

Kim H.C., Bishnoi P.R., Heidemann R.A., Rizvi S.S.H. (1987) Kinetics of methane hydrate decomposition, Chem. Eng. Sci. 42, 7, 1645-1653.

Klauda J.B., Sandler S.I. (2005) Global distribution of methane hydrate in ocean sediment, Energy Fuels 19, 2, 459-470.

Lijun Y., Guangjin C., Weixin P., Jiang L. (2005) Experimental and Modeling Study on Hydrate Formation in Wet Activated Carbon, J.Phys. Chem. B 109, 12, 6025-6030.

Makogon Y.F., Holditch S.A. (2001) Experiments illustrate hydrate morphology and kinetics, Gas Oil J.99, 7, 45-50.

Makogon Y.F. (2010) Natural gas hydrates - A promising source of energy, J. Nat. Gas Sci.Eng. 2, 1, 49-59.

Masuda Y., Konno Y., Kurihara M., Ouchi H., Kamata Y., Ebinuma T., Narita H. (2005) Validation study of numerical simulator predicting gas production performance from sediments containing methane hydrates, Proceedings of the 5th International Conference on Gas Hydrates, Trondheim, Norway, June 12-16.

Moridis G.J., Sloan E.D. (2007) Gas production potential of disperse low-saturation hydrate accumulations in oceanic sediments, Energy Convers. Manage. 48, 6, 1834-1849.

Sloan E.D., Carolyn A.K. (2008) Clathrate Hydrates of Natural Gas, 3rd ed., CRC Press, New York.

Final manuscript received in October 2011 Published online in May 2012

\section{Copyright (C) 2012 IFP Energies nouvelles}

Permission to make digital or hard copies of part or all of this work for personal or classroom use is granted without fee provided that copies are not made or distributed for profit or commercial advantage and that copies bear this notice and the full citation on the first page. Copyrights for components of this work owned by others than IFP Energies nouvelles must be honored. Abstracting with credit is permitted. To copy otherwise, to republish, to post on servers, or to redistribute to lists, requires prior specific permission and/or a fee: Request permission from Information Mission, IFP Energies nouvelles, fax.+33147527096, or revueogst@ifpen.fr. 